Table. Familial risks and heritability of AS by type of first-degree relative (FDR) and sex Overall Male-male Male-female Female-male Femalefemale

\begin{tabular}{|c|c|c|c|c|c|}
\hline Relative with & \multicolumn{5}{|c|}{ Familial risk, odds ratio $(95 \% \mathrm{Cl})$} \\
\hline Sibling & $\begin{array}{c}19.5(16.9- \\
22.4)\end{array}$ & $\begin{array}{c}19.9(16.1- \\
24.7)\end{array}$ & $\begin{array}{c}20.9(16.0- \\
27.4)\end{array}$ & $\begin{array}{c}20.5(16.0- \\
26.5)\end{array}$ & $\begin{array}{c}21.0(13.3- \\
33.2)\end{array}$ \\
\hline Parent & $\begin{array}{c}19.1(17.2- \\
21.3)\end{array}$ & $\begin{array}{c}18.3(15.5- \\
21.6)\end{array}$ & $\begin{array}{c}20.8(16.3- \\
26.4)\end{array}$ & $\begin{array}{c}14.1(11.3- \\
17.5)\end{array}$ & $\begin{array}{c}34.2(26.1- \\
44.9)\end{array}$ \\
\hline Child & $\begin{array}{c}20.6(18.2- \\
23.3)\end{array}$ & $\begin{array}{c}20.5(16.8- \\
25.1)\end{array}$ & $\begin{array}{c}16.0(12.2- \\
21.0)\end{array}$ & $\begin{array}{c}19.9(15.0- \\
26.4)\end{array}$ & $\begin{array}{c}26.2(18.5- \\
37.2)\end{array}$ \\
\hline Any FDR & $\begin{array}{c}19.4(18.1- \\
20.8)\end{array}$ & $\begin{array}{c}19.0(17.2- \\
21.1)\end{array}$ & $\begin{array}{c}18.2(15.9- \\
21.0)\end{array}$ & $\begin{array}{c}17.7(15.4- \\
20.3)\end{array}$ & $\begin{array}{c}26.9(22.0- \\
32.9)\end{array}$ \\
\hline \multirow[t]{2}{*}{$>1$ relative } & $\begin{array}{c}68.0(51.3- \\
90.1)\end{array}$ & & & & \\
\hline & \multicolumn{5}{|c|}{ Heritability $(95 \% \mathrm{Cl})$} \\
\hline Siblings & $\begin{array}{c}0.77 \\
(0.73-0.80)\end{array}$ & $\begin{array}{c}0.80 \\
(0.74-0.85)\end{array}$ & $\begin{array}{c}0.73 \\
(0.67-0.78)\end{array}$ & $\begin{array}{c}0.77 \\
(0.72-0.83)\end{array}$ & $\begin{array}{c}0.71 \\
(0.61-0.81)\end{array}$ \\
\hline
\end{tabular}

Disclosure of Interests: None declared

DOI: 10.1136/annrheumdis-2019-eular.1949

\section{FRI0370 ACCELERATED EXTRACELLULAR MATRIX REMODELING IN PSORIATIC ARTHRITIS \& VALUE OF ECM-RELATED BIOMARKERS}

Samra Sardar ${ }^{1}$, Salome Kristensen ${ }^{2}$, Anne Sofie Siebuhr ${ }^{1}$, Jeppe Christensen ${ }^{3}$, Morten Karsdal ${ }^{1}$, Annette Mortensen ${ }^{2}$, Anne-Christine Bay-Jensen ${ }^{1} .{ }^{1}$ Nordic Bioscience, Copenhagen, Denmark; ${ }^{2}$ Aalborg University Hospital, Department of Rheumatology, Aalborg, Denmark; ${ }^{3}$ Aalborg University Hospital, Department of Nephrology, Aalborg, Denmark

Background: With our increasing understanding of cross-talk between the immune system (immune cells, cytokines) and extracellular matrix (ECM) of the affected tissues, ECM destruction and turnover has gained a lot of attention in inflammatory arthritis. ECM mainly consists of interstitial matrix (rich in type I and III collagens) and basement membrane (mainly composed of type IV collagen), both of which are affected in inflammatory arthritis. We hypothesize that inflammatory milieu in Psoriatic Arthritis (PsA) leads to accelerated ECM destruction and remodeling, and the release of ECM metabolites into circulation, that can be measured in serum as biomarkers of tissue remodeling and may give insight to pathological process at the tissue level.

Objectives: This prospective study aimed to use serological biomarkers for evaluation of the extent of damage to, and changes in turnover of ECM in patients with PSA and to investigate their relation to inflammatory biomarkers and disease activity.

Methods: Patients with PSA $(n=145)$ fulfilling the CASPAR criteria and above 18 years of age with any disease activity were recruited through outpatient department in Aalborg University Hospital, Denmark. Exclusion criteria were pregnancy, treatment with biological DMARD, or with oral corticosteroids and other comorbidities. Clinical disease parameters were recorded, and blood samples were collected at baseline and 24 weeks follow-up. Inflammation-related ECM remodelling was measured by serological biomarkers of type I, III and IV collagen formation (Pro-C1, ProC3 and Pro-C4, respectively) and MMP-mediated degradation (C1M, C3M and $\mathrm{C} 4 \mathrm{M}$ respectively). The chronic inflammation was measured by CRPM (MMP degraded metabolite of CRP). All biomarkers were measured by competitive ELISAs and levels were compared to the reference levels of healthy individuals. The biomarker data was $\log _{2}$ transformed for normalization and standard parametric statistical methods were applied.

\begin{tabular}{|l|r|r|r|r|r|r|c|c|}
\hline \multirow{2}{*}{$\begin{array}{l}\text { Biomarkers } \\
\text { (ng/ml) }\end{array}$} & \multicolumn{3}{|c|}{ PsA patients } & \multicolumn{3}{c|}{ Reference values* } & \multicolumn{2}{c|}{ Statistics } \\
\cline { 2 - 9 } & Mean & SD & \multicolumn{1}{l|}{ n } & \multicolumn{1}{l|}{ Mean } & \multicolumn{1}{l|}{ SD } & n & Difference & P Value \\
\hline C1M & 50.00 & 32.18 & 145 & 24.8 & 10.8 & 29 & 25.2 & $<0.0001$ \\
\hline C3M & 10.94 & 3.15 & 145 & 9.69 & 2.59 & 127 & 1.25 & 0.0004 \\
\hline C4M2 & 29.57 & 10.51 & 145 & 21.33 & 5.64 & 89 & 8.24 & $<0.0001$ \\
\hline Pro-C1 & 79.20 & 38.85 & 145 & 104.77 & 54.17 & 119 & -25.57 & $<0.0001$ \\
\hline Pro-C3 & 11.49 & 3.56 & 145 & 11.28 & 3.56 & 111 & 0.21 & ns \\
\hline Pro-C4 & 304.07 & 120.17 & 145 & 204.88 & 63.54 & 127 & 99.19 & $<0.0001$ \\
\hline
\end{tabular}

\begin{tabular}{|c|c|c|c|c|c|c|}
\hline & $\begin{array}{l}\log _{2} \\
\Delta \mathrm{C1M}\end{array}$ & $\log _{2} \Delta C 3 M$ & $\log _{2} \Delta C 4 M$ & $\begin{array}{c}\log _{2} \Delta \text { Pro- } \\
C 1\end{array}$ & $\begin{array}{c}\log _{2} \Delta \text { Pro- } \\
C 3\end{array}$ & $\begin{array}{c}\log _{2} \Delta \text { Pro- } \\
C 4\end{array}$ \\
\hline$\Delta$ CRP & $0.621 \neq$ & $0.53 \neq$ & $0.341 \neq$ & -0.062 & 0.098 & $0.267^{+}$ \\
\hline $\log _{2} \Delta$ CRPM & $0.436 \neq$ & $0.615 \ddagger$ & $0.415 \ddagger$ & 0.097 & 0.208 & $0.393 \ddagger$ \\
\hline$\triangle$ ASDAS & $0.202^{*}$ & $0.21^{*}$ & $0.207^{*}$ & 0.042 & 0.104 & $0.204^{*}$ \\
\hline$\triangle B$ BSDAI & 0.032 & 0.102 & 0.148 & 0.03 & 0.057 & 0.117 \\
\hline$\triangle B A S M I$ & 0.015 & 0.005 & 0.107 & -0.015 & -0.061 & $0.175^{*}$ \\
\hline$\triangle P A S I$ & -0.076 & -0.033 & -0.001 & -0.09 & -0.053 & 0.008 \\
\hline$\Delta$ LEI & -0.024 & 0.027 & $0.246 t^{t}$ & 0.108 & -0.043 & 0.094 \\
\hline$\triangle$ SPARCC & 0 & 0.152 & 0.163 & 0.018 & -0.049 & 0.174 \\
\hline$\Delta \mathrm{SJC}$ & -0.015 & -0.144 & 0.153 & -0.011 & 0.019 & 0.062 \\
\hline$\Delta \mathrm{TJC}$ & -0.039 & 0.037 & 0.062 & 0.006 & -0.006 & 0.077 \\
\hline$\Delta$ VAS-Pain & 0.07 & 0.104 & 0.138 & 0.075 & 0.087 & $0.198^{*}$ \\
\hline
\end{tabular}

Results: We found that there was an increase in the degradation of interstitial matrix (represented by $\mathrm{C} 1 \mathrm{M}$ and $\mathrm{C} 3 \mathrm{M}$ ) which was uncompensated with either decreased (Pro-C1) or unaltered (Pro-C3) formation in patients with PsA as compared to healthy individuals. On the contrary there was a compensated increase in basement membrane remodeling in patients with PSA as represented by increase in both C4M and Pro-C4 in comparison to healthy individuals (Table 1). Interestingly, there was a strong correlation between baseline C4M and Pro-C4 $(r=0.703, p<0.0001)$, and 24-week changes in both biomarkers $(r=0.468, p<0.0001)$ pointing towards coupling between the two processes which was either lost or was weak in case of interstitial collagens. As baseline values and changes in $\mathrm{C} 1 \mathrm{M}, \mathrm{C} 3 \mathrm{M}, \mathrm{C} 4 \mathrm{M}$ and Pro-C4 showed a strong correlation with changes in inflammatory biomarkers, we believe that ECM remodeling in PsA is, at least partly, driven by inflammation. Furthermore, baseline values and changes in these ECM turnover biomarkers correlated positively with changes in composite disease activity scores (Table 2) that may indicate their clinical importance as potential diagnostic or disease activity markers.

Conclusion: Chronic inflammation underlying PsA pathology results in an increased amount of ECM turnover that correlates with clinical progression and can be measured by serological biomarkers.

\section{REFERENCES}

None

Disclosure of Interests: Samra Sardar Employee of: I am a full time employee at Nordic Bioscience, Salome Kristensen: None declared, Anne Sofie Siebuhr Employee of: I am a full-time employee in Nordic Bioscience, Jeppe Christensen: None declared, Morten Karsdal Shareholder of: I own shares of Nordic Bioscience, Employee of: I am a full-time employee in Nordic Bioscience, Annette Mortensen: None declared, AnneChristine Bay-Jensen Shareholder of: I own shares of Nordic Bioscience, Employee of: I am a full-time employee in Nordic Bioscience

DOI: 10.1136/annrheumdis-2019-eular.5576

\section{FRI0371 ALTERED EXPRESSION OF LNCRNA NR_003542 AND NR_026756 IN ANKYLOSING SPONDYLITIS MIGHT BE ASSOCIATED WITH THE DISEASE ACTIVITY}

Ting Yi, Yu-Feng Qing, Zi-Yi Tang, Jian-Xiong Zheng, Dan Wang, Qin Xiong Affiliated Hospital of North Sichuan Medical College, Nanchong, China

Background: IncRNAs have been recognized as powerful regulators of numerous genes and pathways in the pathogenesis of inflammatory and autoimmune diseases, including SLE, RA, T1DM, MS, autoimmnue thyroid disease, Sjögren's syndrome psoriasis, and Crohn's disease[1]. The role of IncRNAs in the pathogenesis of Ankylosing Spondylitis (AS) is just beginning to be investigated

Objectives: To determine whether the altered expression of IncRNA NR 003542 and NR 026756 in peripheral blood of AS patients could provide insights into the pathogenesis of AS.

Methods: Peripheral blood mononuclear cells (PBMCs) IncRNA NR_003542 and NR_026756 expression were measured in 30 active AS (AAS)group, 30 inactive AS (IAS) group and 30 healthy control $(\mathrm{HC})$ subjects. Clinical characteristics of the subjects are summarized in Table1. Results: 1. Clinical and laboratory characteristics of the three groups (Table 1) 
Table 1. Clinical and laboratory characteristics of subjects studied

\begin{tabular}{lcccc}
\hline & $\mathrm{AAS}(n=30)$ & $\mathrm{IAS}(n=30)$ & $\mathrm{HC}(n=30)$ & $P$ value \\
\hline Gender, F/M & $8 / 22$ & $8 / 22$ & $10 / 20$ & 0.805 \\
Age, mean $\pm S D$ (years) & $36.23 \pm 10.86$ & $33.47 \pm 10.42$ & $35.8 \pm 10.84$ & 0.467 \\
Disease duration, mean $\pm \mathrm{SD}$ (years) & $9.55 \pm 6.34$ & $7.8 \pm 6.55$ & - & 0.205 \\
Family history,positive/tested (\%) & $4 / 30(13.33 \%)$ & $2 / 30(6.67 \%)$ & - & 0.667 \\
BASDAI, mean $\pm S D$ & $5.2 \pm 0.98$ & $2.24 \pm 1.31$ & - & 0.000 \\
BASFI, mean $\pm S D$ & $3.2 \pm 2.34$ & $0.74 \pm 0.99$ & - & 0.000 \\
Uveitis,positive/tested $(\%)$ & $6 / 30(20 \%)$ & $3 / 30(10 \%)$ & - & 0.470 \\
CT grading of sacroiliac arthritis, & $5 / 14 / 11$ & $12 / 14 / 4$ & - & $0.014^{\text {a }}$ \\
II/III/IV & & & & \\
HLA-B27,positive/tested $(\%)$ & $29 / 30(96.67 \%)$ & $25 / 30(83.33 \%)$ & - & 0.000 \\
ESR, mean $\pm S D(m m / h)$ & $58.83 \pm 27.04$ & $15.63 \pm 12.75$ & $5.97 \pm 3.18$ & 0.000 \\
hsCRP, mean $\pm S D(\mathrm{mg} / \mathrm{L})$ & $36.6 \pm 31.14$ & $5.9 \pm 5.54$ & $1.09 \pm 2.11$ & 0.000 \\
WBC, mean $\pm S D\left(10^{9 *} / \mathrm{L}\right)$ & $7.99 \pm 1.62$ & $6.98 \pm 1.81$ & $5.94 \pm 1.09$ & 0.028 \\
GLOB, mean $\pm S D(\mathrm{~g} / \mathrm{L})$ & $40.3 \pm 6.08$ & $33.44 \pm 3.93$ & $32.85 \pm 4.55$ & 0.000 \\
\hline
\end{tabular}

$B A S D A$ : bath ankylosing spondylitis disease activity index, $B A S F I$ : bath ankylosing spondylitis functional index,HLA-B27:Human leukocyte antigen B27.ESR: erythrocyte sedimentation, $W B C$ :leukocyte, GLOB: globulin, a: the $P$ value of the non-parametric Mann-Whitney test.

2. Comparison of the two IncRNAs expression among the three groups (Figure 1)

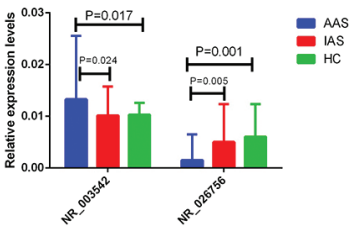

Figure 1. Expression of IncRNA-NR_003542 and NR_026756 among three groups

3. Correlations between levels of two IncRNAs expression $s$ and clinical data in AS patients (Figure 2)
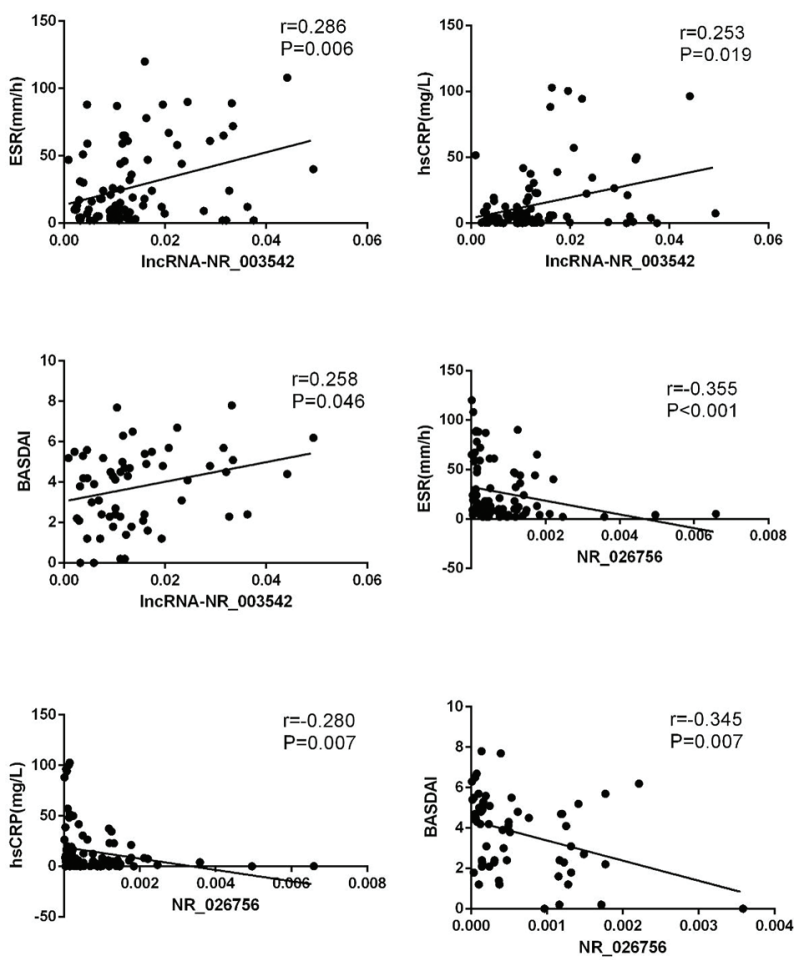

Figure 2. Correlations between levels of two IncRNAs expression and clinical data in AS patients
Conclusion: Altered expression of IncRNA-NR_003542 and NR_026756 in peripheral blood of AS patients might be involved in the pathogenesis of AS, higher expression of IncRNA-NR_003542 and lower expression of NR_026756 might be as the biomarkers for the disease activity of AS, further study would be needed to expound on the exact role of the two IncRNAs in AS.

\section{REFERENCES:}

[1] Chatenoud, L. Immune therapies of autoimmune diseases: are we approaching a real cure? Curr Opin Immunol 18, 710-7 (2006).

Disclosure of Interests: Ting Yi: None declared, Yu-Feng Qing Grant/ research support from: Sichuan Youth Science and Technology (2016JQ0053), and the Department of Science and Technology of Sichuan Province (2018JY0257), Zi-Yi Tang: None declared, Jian-Xiong Zheng: None declared, Dan Wang: None declared, qin xiong: None declared

DOI: 10.1136/annrheumdis-2019-eular.7312

\section{Spondyloarthritis - treatment}

\section{FRI0372 DMARD TREATMENT AND OPIOID USE IN EARLY SPONDYLOARTHRITIS IN FINLAND}

Paula Muilu' ${ }^{1}$, Vappu Rantalaiho ${ }^{2,3}$, Hannu Kautiainen ${ }^{4,5}$, Lauri Virta $^{6}$

Kari Puolakka ${ }^{7}{ }^{1}$ Tampere University Hospital, Department of Medicine, Tampere, Finland; ${ }^{2}$ Tampere University Hospital, Centre for Rheumatic Diseases, Tampere, Finland; ${ }^{3}$ Tampere University Hospital, Faculty on Medicine and Health

Technology, Tampere, Finland; ${ }^{4}$ University of Helsinki and Helsinki University Hospital, Department of General Practice and Primary Health Care, Helsinki, Finland; ${ }^{5}$ Turku University Hospital, Unit of Primary Health Care, Turku, Finland; ${ }^{6}$ Social Insurance Institution of Finland, Research Department, Turku, Finland;

${ }^{7}$ South Karelia Central Hospital, Department of Medicine, Lappeenranta, Finland

Background: Disease-modifying anti-rheumatic drugs (DMARDs) are introduced for the treatment of spondyloarthritis $(\mathrm{SpA})$ after failure of non-steroidal anti-inflammatory drugs (NSAIDs). In Finland, try out with a conventional synthetic DMARD (csDMARD) is required before initiation of biologicals (bDMARD). The patients with DMARDs are eligible for a higher reimbursement for the cost of medication. Opioids are not recommended for arthritis pain.

Objectives: To report the current DMARD and pain medication use among newly-onset SpA patients in Finland.

Methods: From the nationwide reimbursement register maintained by the Social Insurance Institution of Finland we collected all incident adult patients with SpA (ICD-10 codes M45-46) between 2010-14 and divided them into two groups depending on whether bDMARDs were subsequently initiated (group B) or not (group A). Patients' drug purchases between 2009-15 were obtained from the Drug Purchase Register. Opioid use by these patients was evaluated one year before and after the index date (ID; the date when special reimbursement for antirheumatic drugs became effective), and compared to age, sex, and place of residence matched population controls. Intravenously administered bDMARDs (e.g. infliximab) were not included.

Results: We identified 3577 SpA patients, 23\% of which started a selfinjected bDMARD during the observation period. More of the patients in group B needed pain medication, prednisolone, methotrexate, or other csDMARDs than sulphasalazine, which was more frequent in group $A$ (table 1). Fifty-eight percent of the patients in group $B$ started their bDMARD already within one year from ID (table 1). Overall, $29.8 \%$ of the SpA patients compared to $8.1 \%$ of the controls purchased opioids at least once during the year before ID. Patients' opioid purchases peaked during the last 3-month period before ID; risk ratios (RR) were 4.23 (95\% confidence interval (Cl) 3.63 to 4.84$)$ and 6.23 (5.23 to 7.41$)$ in patient groups A and B, respectively, compared to controls. SpA patients who had at least one opioid purchase during 12 months preceding the ID were 1.58 times more likely to start a bDMARD than those who did not purchase any opioids.

Conclusion: Only one of four early SpA patients in Finland were initiated a self-injected bDMARD during 2010-15. The use of opioids before SpA diagnosis appears to be nearly four times more common among SpA patients compared to population controls, and early opioid purchases may act as a surrogate marker for further bDMARD initiation. 